\title{
Avaliação de desempenho e tomada de decisão em bibliotecas universitárias
}

Discente: Carla Purcina de Campos Pereira Orientador: Dr. Gregorio Varvakis Rados - PGCIN/UFSC

Banca: Dra. Edna Lúcia da Silva - PGCIN/UFSC

Dra. Magda Teixeira Chagas - PGCIN/UFSC

Dra. Delsi Fries Davok - DBI/UDESC

\section{RESUMO}

A finalidade de utilizar indicadores de desempenho nas bibliotecas universitárias brasileiras é prover informações para a tomada de decisão e assim promover qualidade no sistema educacional. Este trabalho analisou os indicadores de desempenho utilizados na gestão das bibliotecas universitárias, para isso caracterizou os modelos de avaliação de desempenho utilizados pelas bibliotecas universitárias, identificando os indicadores de desempenho, como estes contribuem no processo de tomada de decisão e caracterizando esse processo de tomada de decisão em bibliotecas universitárias com base nos indicadores. Na pesquisa, analisaram-se os indicadores de desempenho para avaliação de bibliotecas universitárias com base na norma ISO 11620 (2008) Information and documentation - Library performance indicators, a qual é subdividida nas categorias: recursos, acesso e infraestrutura; uso; eficiência; e, potencialidades e desenvolvimento, compostas por quarenta e quatro indicadores. Para isso, foram identificados e caracterizados os indicadores de desempenho utilizados nas bibliotecas universitárias de 353 instituições de ensino superior brasileiras. Em um segundo momento, verificou-se a relevância dos indicadores de desempenho com os gestores/coordenadores de 78 bibliotecas universitárias brasileiras. A partir da análise dos dados coletados, evidenciou-se que os indicadores possuem relevância para a tomada de decisão, uma vez que mais da metade dos indicadores apresentados foram considerados relevantes para a tomada de decisão, no entanto constatou-se uma discrepância entre o uso e a relevância dos indicadores de desempenho para tomada de decisão. Constatou-se, também, que o conjunto de indicadores aplicados às bibliotecas universitárias são em geral os mesmos impetrados pela avaliação do Ministério da Educação, realizado por meio do Sistema Nacional de Avaliação do Ensino Superior. Identificaram-se discrepâncias entre o uso dos indicadores relacionados, concluindo-se que indicadores com o mesmo objetivo em determinados momentos são aplicados em outros não o são. Por fim, conclui-se que uma adequada gestão dos indicadores de 
oferecidos, e, por conseguinte a qualidade do ensino das instituições de ensino superior.

Palavras-chave: Sistema de avaliação. Indicadores de desempenho. Processo de tomada de decisão. Bibliotecas universitárias. 